\title{
Recent Hydrodynamics Improvements to the RELAP5-3D Code
}

\author{
ICONE 17
}

Richard A. Riemke

Cliff B. Davis

Richard R. Schultz

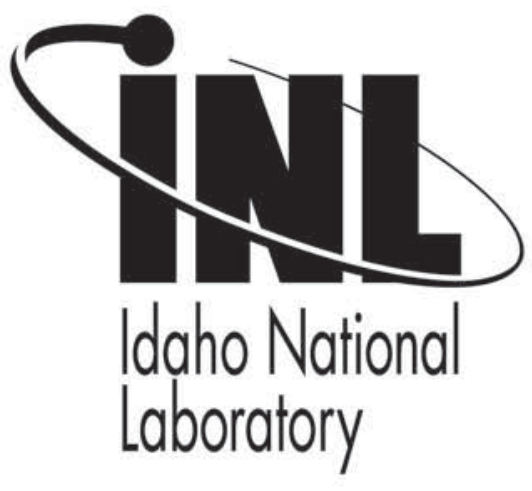

This is a preprint of a paper intended for publication in a journal or proceedings. Since changes may be made before publication, this preprint should not be cited or reproduced without permission of the author. This document was prepared as an account of work sponsored by an agency of the United States Government. Neither the United States Government nor any agency thereof, or any of their employees, makes any warranty, expressed or implied, or assumes any legal liability or responsibility for any third party's use, or the results of such use, of any information, apparatus, product or process disclosed in this report, or represents that its use by such third party would not infringe privately owned rights. The views expressed in this paper are not necessarily those of the United States Government or the sponsoring agency. 


\title{
ICONE17-75380
}

\section{RECENT HYDRODYNAMICS IMPROVEMENTS TO THE RELAP5-3D CODE}

\author{
Richard A. Riemke \\ Idaho National Laboratory, Idaho Falls, Idaho \\ 83415-3890, USA \\ Phone: 208-526-0697 \\ Fax: 208-526-0528 \\ Email: Richard.Riemke@inl.gov
}

\author{
Cliff B. Davis \\ Idaho National Laboratory, Idaho Falls, Idaho \\ 83415-3890, USA \\ Phone: 208-526-9470 \\ Fax: 208-526-0528 \\ Email: Cliff.Davis@inl.gov
}

\author{
Richard R. Schultz \\ Idaho National Laboratory, Idaho Falls, Idaho \\ 83415-3890, USA \\ Phone: 208-526-9508 \\ Fax: 208-526-0528 \\ Email: Richard.Schultz@inl.gov
}

\begin{abstract}
The hydrodynamics section of the RELAP5-3D computer program has been recently improved. Changes were made as follows: (1) improved turbine model, (2) spray model for the pressurizer model, (3) feedwater heater model, (4) radionuclide transport model, (5) improved pump model, and (6) compressor model. These changes will be discussed.
\end{abstract}

\section{INTRODUCTION}

The RELAP5 series of codes has been developed at the Idaho National Laboratory for over 25 years under sponsorship of the U. S. Department of Energy, the U. S. Nuclear Regulatory Commission, members of the International Code Assessment and Applications Program, members of the Code Applications and Maintenance Program, and members of the International RELAP5 Users Group. Specific world-wide applications of the code have included simulations of transients of light water reactor systems such as loss of coolant, anticipated transients without scram, and operational transients such as loss of feedwater, loss of offsite power, station blackout, and turbine trip. RELAP5-3D (Ref. 1), the latest in the series of RELAP5 codes, extends the applicability of earlier versions to include an integrated multidimensional thermalhydraulic/neutronic capability. In addition to calculating the behavior of a reactor coolant system during a transient, it can be used for simulation of a wide variety of hydraulic and thermal transients in both nuclear and nonnuclear systems involving mixtures of vapor, liquid, noncondensable gases, and nonvolatile solute. The 3D capability in RELAP5-3D includes 3D hydrodynamics and 3D neutron kinetics [the 3D neutronics is based on the NESTLE code (Ref. 2)]. RELAP5-3D was recently modified to include all the ATHENA (Ref. 3) features and models that were previously only available in the ATHENA configuration. The ATHENA features and models are currently used primarily in Generation IV reactor applications, GNEP reactor applications, space reactor applications, and nuclear fusion applications.

RELAP5-3D is also used in a SCDAP/RELAP5-3D (Ref. 4) configuration that is designed to calculate for severe accident situations the overall reactor coolant system thermalhydraulic response, core damage progression, and reactor vessel heatup and damage. RELAP5-3D (also true of SCDAP/RELAP5-3D) is also used in an integrated code system configuration consisting of RELAP5-3D and other codes such as FLUENT, CFX, and CONTAIN. The coupling of the codes 
in this configuration is coordinated using an executive program (Ref. 5) in concert with the Parallel Virtual Machine (PVM) message passing software. The coupling can be done explicitly or semi-implicitly. For example, the FLUENT/RELAP5-3D (Ref. 6) coupling configuration is designed to perform detailed 3D analyses using FLUENT's capability while the boundary conditions required by the FLUENT calculation are provided by the balance-of-system model created using RELAP5-3D. The FLUENT/RELAP5-3D coupling configuration is currently used primarily in Generation IV reactor applications. RELAP5-3D is also used for the thermal-hydraulic module in the real-time nuclear plant simulation code RELAP5-R/T (Refs. $7,8,9$ ), which is used in training simulators at nuclear power plants around the world. There is also a visualization system for the various RELAP5-3D configurations, which is called the RELAP5-3D Graphical User Interface (RGUI) (Ref. 10).

This paper provides an overview of the hydrodynamics models in RELAP5-3D and then discusses the recent additions/improvements to the hydrodynamics model in the RELAP5-3D computer program.

\section{HYDRODYNAMICS MODEL}

The RELAP5-3D hydrodynamics model is a transient, two-fluid model for flow of a two-phase vapor/gas-liquid mixture than can contain noncondensable components in the vapor/gas phase and/or a soluble component (i.e., boron) in the liquid phase and/or radionuclides in the vapor/gas and the liquid phase. A one-dimensional as well as a multi-dimensional hydrodynamics model is included in the code. The hydrodynamics model is based on the PILOT code (Refs. 11, $12,13)$ developed at the Idaho National Laboratory.

The two-fluid equations of motion that are used as the basis for the RELAP5-3D hydrodynamics model are formulated in terms of volume and time-averaged parameters of the flow. Phenomena that depend upon transverse gradients, such as friction and heat transfer, are formulated in terms of the bulk properties using empirical transfer coefficient formulations. In situations where transverse gradients cannot be represented within the framework of empirical transfer coefficients, such as subcooled boiling, additional models specially developed for the particular situation are employed. The system model is solved numerically using a semi-implicit finite-difference technique. The user can select an option for solving the system model using a nearly-implicit finite-difference technique, which allows violation of the material Courant limit. This option is suitable for steady-state calculations and for slowly varying, quasi-steady transient calculations.

The basic two-phase model is supported is supported by constitutive models for interphase drag, interphase mass transfer, wall heat transfer, and wall friction. All of these constitutive models are closely related through the geometry of the two-phase mixture or the flow regime. The interphase drag and wall friction models dominate the nonhomogeneous character of the flow, while the interphase mass transfer and wall heat transfer models dominate the nonequilibrium character of the mixture.

Special process models are incorporated into the basic hydrodynamic model for phenomena that are either too complex for mechanistic modeling or involve large spatial gradients and would require fine nodalization to accurately resolve. RELAP5-3D contains models for the following special processes: choking, stratification entrainment/pullthrough, abrupt area change, user-specified form loss, cross flow junction, water packing mitigation scheme, countercurrent flow limitation, mixture level tracking, thermal stratification, jet junction, magnetohydrodynamics, and variable volume.

A generic modeling approach is used in which hydrodynamics components are "built" by means of code input from basic code components such as fluid control volumes, junctions, pipes, branches, etc. The general philosophy has been to avoid system component models such as steam generator and core. Some subsystem components are unavoidable due to unique processes or performance. RELAP5-3D contains models for the following subsystems components: separator, jet mixer, pump, turbine, valve, accumulator, ECC mixer, annulus, pressurizer, feedwater heater, and compressor.

\section{IMPROVED TURBINE MODEL}

A turbine is a device that converts energy contained in high-pressure fluid to mechanical work. The complicated configuration of a turbine precludes a complete first-principles model, at least for the purpose of system transient calculations. A lumped-parameter turbine model is used in RELAP5-3D wherein a sequence of turbine stages (henceforth referred to as a stage group) is treated as a single-junction and single-volume. The stage group is then represented using modified energy, continuity, and momentum equations. An efficiency factor based upon simple momentum and energy considerations is used to represent the nonideal internal processes.

The first improvement to the turbine model is the addition of dissipation to the turbine energy equation, additional models to account for variable frictional torque, variable moment of inertial, and a new type of turbine in which the user can specify the efficiency as a function of normalized speed and load. With the addition of dissipation to the turbine energy equation, the turbine hydraulic power now matches the shaft power.

The second improvement to the turbine model is the addition of a moisture separator model. The second junction of a turbine component originally served as a steam extraction 
junction. With the improvement, the second turbine junction now serves as either a steam extraction junction or as a moisture separator junction. When selecting the moisture separator junction option, the user specifies a moisture separator efficiency for the second junction of a turbine component; this results in the code computing a liquid velocity for this second junction that will remove the user specified fraction of the liquid in the turbine volume during the current time step.

\section{SPRAY MODEL FOR PRESSURIZER MODEL}

The pressurizer component is identical to a pipe component, except the user must input the surgeline connection junction identifier. The surgeline connection junction is not part of the pressurizer component. There are optional input for a constant interfacial heat transfer coefficient for liquid and vapor/gas in the vertically stratified flow regime and the level tracking flow regime, a multiplier on the film thickness in the annular-mist flow regime, and a multiplier on the interfacial heat transfer coefficients for both the liquid and vapor/gas in the vertically stratified flow regime and level tracking flow regime.

The first improvement to the pressurizer model is an optional spray model junction identifier (indicates spray junction and activates the spray model) and an optional pressurizer spray droplet size (allows the user to input the spray droplet size; if not entered, the code-calculated droplet size is used). The spray droplet size is a function of the spray nozzle geometry and is therefore a plant-specific data item.

The second improvement to the pressurizer model is a spray induced, enhanced pool condensation model. This model uses the spray flow rate into the liquid pool (calculated from code quantities), relevant enthalpies, and a user-input geometryspecific mixing coefficient (determined from experimental data).

\section{FEEDWATER HEATER MODEL}

The feedwater heat model is recent new model to RELAP5-3D, and it is used to model horizontally-oriented tube-in-shell heat exchangers typically found in nuclear power plants. Steam extracted from a turbine flows into the top of the shell, condenses on the tubes carrying the cool feedwater, and flows out the bottom.

The code treats the heat transfer process within the shell as consisting of condensation above the water level and convection below it. Optional input may be entered to specify the relationship between the void fraction within the shell and the corresponding water level. In addition, for heat slabs representing the tube bundle walls, input is required to specify the elevation of the top and bottom of the tube bundle relative to the bottom of the shell. Input is also required to specify the number of tubes in vertical alignment, since this term is used in the condensation heat transfer correlation.

As is the case in an actual nuclear power plant, a control system is required to control the water level in the shell to obtain the necessary heat transfer to achieve a desired feedwater outlet temperature. Normally, a sum and proportionintegral controller is used in conjunction with a servo valve to control the flow of condensate leaving the shell.

\section{RADIONUCLIDE TRANSPORT MODEL}

The radionuclide transport model is recent new model to RELAP5-3D, and it is used to simulate the transport of radioactive or fertile nuclides in the reactor coolant systems (fertile nuclides are those nuclides that can be made radioactive by neutron capture).

The radionuclide species may be transported by either the liquid or vapor/gas phases. A radioactive species may be created by neutron absorption in a fertile specie [i.e., N16 may be created by an $(n, p)$ reaction with $\mathrm{O} 16$ in the water coolant in the reactor core] or may be injected into the coolant system using general tables or control variables. For example, general tables or control variables may be used to model the release of radionuclide specie from fuel rods due to bursting during a transient or through pinhole leaks that develop due to erosion, fretting, or manufacturing defects in the fuel rod cladding or through leaching of the nuclide from the structural material in a reactor system (i.e., Co59; is leached out of steel in the reactor system by the coolant and becomes available to be transmuted to Co60 through neutron capture as it circulates through the reactor core). A radioactive species may also be destroyed by neutron absorption (i.e., transmuted to a radioactive or nonradioactive daughter specie). The concentrations of radionuclide species are assumed to be sufficiently dilute that assumptions similar to those for the boron transport model in RELAP5-3D are valid.

\section{IMPROVED PUMP MODEL}

The basic approach to pump modeling is to superimpose a quasi-static model for pump performance on the RELAP5-3D volume-junction flow path representation. The pump is volume-oriented component, and the head developed by the pump is apportioned equally between the suction and discharge junctions that connect the pump volume to the system. The pump model interfaced with the two-fluid hydrodynamic model by assuming the head developed by the pump is similar to a body force. Thus the head term appears in the mixture momentum equation; but, like the gravity body force, it does not appear in the difference momentum equation used in RELAP5-3D. There are options for a motor-driven pump. The 
pump can be linked to a shaft component, and thus can be driven by either a motor or a turbine.

The improvement to the pump model is to the pump frictional torque. Previously, this torque was modeled as a cubic function of the pump rotational velocity. Now, this torque is modeled as a four-term function of the pump rotational velocity where the terms are raised to a user-input variable power. Also, previously there was no allowed user input of the pump critical speed ratio. Now, there is optional user input of the pump critical speed ratio. When the absolute value of the pump speed ratio is less than the pump critical speed ratio, the pump frictional torque is taken from a new additional user input limit value.

\section{COMPRESSOR MODEL}

The compressor model is recent new model to RELAP5-3D, and it is similar to the existing pump model in RELAP5-3D. It performs the same function on a gas as the pump performs on single-phase and two-phase fluids. The compressor can be connected to a shaft. A shaft is used when the compressor is driven by a turbine or by an electric motor with a control system to regulate speed. The compressor also may optionally include input for an electric motor to drive the compressor.

It is anticipated that the compressor will usually be driven by a turbine on the same shaft, although other capabilities presently available in the pump, i.e., the speed table, the motor torque table, and the coastdown feature are also available in the compressor. The compressor head curve is specified differently than that of the pump homologous curves, and the compressor torque is calculated based on the characteristic curves and the stage efficiency. The compressor consists of an inlet junction, a control volume, and, optionally, an outlet junction. The outlet junction can also be an ordinary junction (i.e., single junction, etc.) or another compressor component.

\section{CONCLUSIONS}

This paper has discussed the hydrodynamics models in the RELAP5-3D computer program. Recent additions /improvements to the hydrodynamics model in the RELAP5$3 \mathrm{D}$ computer program were then discussed, which are the following: improved turbine model, spray model for the pressurizer model, recent new feedwater heater model, recent new radionuclide transport model, improved pump model, and recent new compressor model.

\section{ACKNOWLEDGMENTS}

This work was funded through the DOE under DOE/NE Idaho Operations Office Contract No. DE-AC07-05ID14517.
This manuscript has been authored by Battelle Energy Alliance, LLC under Contract No. DE-AC07-05ID14517 with the U.S. Department of Energy. The United States Government retains and the publisher, by accepting the article for publication, acknowledges that the United States Government retains a nonexclusive, paid-up, irrevocable, world-wide license to publish or reproduce the published form of this manuscript, or allow others to do so, for United States Government purposes.

\section{REFERENCES}

1. The RELAP5-3D Code Development Team, 2005, "RELAP5-3D Code Manual," INEEL-EXT-98-00834, Revision 2.4, June, http://www.inel.gov/relap5/r5manuals.htm.

2. Turinsky, P., et al., 1994, "NESTLE: A Few-Group Neutron Diffusion Equation Solver Utilizing the Nodal Expansion Method for Eigenvalue, Adjoint, Fixed-Source Steady State and Transient Problems," EGG-NRE-11406, June.

3. Johnsen, G., C. Davis, and P. Bayless, 2004, ATHENA-3D for Generation IV Reactor Analysis, BE-2004, American Nuclear Society Winter Meeting, Washington DC, USA, November 14-18, http://www.inel.gov/relap5/athena/athena.htm.

4. The SCDAP/RELAP5-3D Development Team, 2003, "SCDAP/RELAP5-3D Code Manual," INEEL-EXT02-00589, Revision 2.2, October, http://www.inel.gov/relap5/scdap/scdap.htm.

5. Weaver, W., E. Tomlinson, and D. Aumiller, 2001, "A PVM Executive Program for Use with RELAP5-3D," 2001 RELAP5 International Users Seminar, Sun Valley, ID, USA, September 5-7, http://www.inel.gov/relap5/rius/sunvalley/weaver.pdf.

6. Schultz, R. and W. Weaver, 2003, "Using the RELAP5-3D Advanced Systems Analysis Code with Commercial and Advanced CFD Software," ICONE$11,11^{\text {th }}$ International Conference on Nuclear Engineering, Tokyo, Japan, April 20-23.

7. Williams, K., 2001, "Full-Scope Simulators Running Real-time RELAP5-R/T," 2001 RELAP5 International Users Seminar, Sun Valley, ID, USA, September 5-7, http://www.inel.gov/relap5/rius/sunvalley/williams.pdf

8. Hiltbrand, D. and K. Williams, 2001, "Utilization of a RELAP5 RCS and Secondary Plant Model in a 
Nuclear Power Plant Training Simulator," 2001

RELAP5 International Users Seminar, Sun Valley, ID, USA, September 5-7,

http://www.inel.gov/relap5/rius/sunvalley/hiltbrandwilliams.pdf.

9. Judd, J., et al., 1996, "High-Fidelity, Real-Time Simulation with RELAP5/NESTLE," American Nuclear Society Winter Meeting, Washington, DC, USA, November 10-14.

10. Mesina, G., 2004, Visualization of RELAP5-3D Best Estimate Code, BE-2004, American Nuclear Society Winter Meeting, Washington, DC., USA, November 14-18, http://www.inel.gov/relap5/products.htm.

11. Trapp, J. and V. Ransom, 1976, "RELAP5 Hydrodynamic Model: Progress Summary - Field Equations," SRD-126-76, June.

12. Ransom, V. and J. Trapp, 1976, "RELAP5 Hydrodynamic Model: Progress Summary - PILOT Code," PG-R-76-013, December.

13. Ransom, V. and J. Trapp, 1978, "RELAP5 Progress Summary-PILOT Code Hydrodynamic Model and Numerical Scheme," CDAP-TR-005, January. 